\title{
"Primary" aggressive chondroblastoma of the humerus: a case report
}

\author{
K Harish*1, MG Janaki² and N Kishore Alva ${ }^{3}$
}

\author{
Address: ${ }^{1}$ Department Of Surgical Oncology, M. S. Ramaiah Medical College \& Hospital, Bangalore - 560054, India, ${ }^{2}$ Department Of Radiation \\ Oncology, M. S. Ramaiah Medical College \& Hospital, Bangalore - 560054, India and ${ }^{3}$ Department Of Pathology, M. S. Ramaiah Medical College \\ \& Hospital, Bangalore - 560054, India \\ Email: K Harish* - drkhari@yahoo.com; MG Janaki - sramesh@bigfoot.com; N Kishore Alva - alvakishore@yahoo.com \\ * Corresponding author
}

Published: 17 March 2004

BMC Musculoskeletal Disorders 2004, 5:9
Received: 12 October 2003

Accepted: 17 March 2004

This article is available from: http://www.biomedcentral.com/147I-2474/5/9

(c) 2004 Harish et al; licensee BioMed Central Ltd. This is an Open Access article: verbatim copying and redistribution of this article are permitted in all media for any purpose, provided this notice is preserved along with the article's original URL.

\begin{abstract}
Background: Chondroblastomas are rare epiphyseal bone tumors. Very few cases with extracortical aggressive soft tissue invasion or metastasis are reported.

Case presentation: We report a 28 year-old adult male who presented with a large swelling over the left shoulder region. Pre-operative imaging revealed a large tumor arising from upper end of humerus with extensive soft tissue involvement necessitating a fore-quarter amputation. Patient received adjuvant radiation.

Conclusions: This patient is one of the largest chondroblastomas to be reported. Although chondroblastomas are typically benign, rarely they can be locally aggressive or metastatic. Early diagnosis and institution of proper primary therapy would prevent mutilating surgeries and recurrences.
\end{abstract}

\section{Background}

Chondroblastoma is a rare epiphyseal benign bone tumor, occurring usually in the second decade and constituting less than $1 \%$ of bone tumors [1]. Since chondroblastomas are slow growing and present with pain and swelling, it is usually treated when relatively small. Treatment consists of curettage and bone grafting. Though it is a benign entity, rarely it could breach the cortex and involve adjacent areas.

Sixty years since chondroblastoma has been identified as a distinct entity, there have been very few reports of virulent behavior in the form of local aggressiveness or metastasis [2]. An important contribution to such a virulent tumor behavior in majority of these reports was surgical intervention followed by recurrent disease. We present a rare non-recurrent disease where the patient harbored the primary disease for 12 years and the aggressive tumor involved the adjacent soft tissues extensively necessitating a fore-quarter amputation. The patient was informed that his case would be published.

\section{Case report}

A 28 year-old male patient consulted us for a large swelling over the anterior aspect of the left shoulder which he had noticed 12 years earlier. The swelling had gradually increased over these years but pain which was negligible earlier had become more nagging over the previous 3 months. He was clinically evaluated 10 years earlier with $\mathrm{X}$-ray and was advised to undergo surgical resection. The patient had refused the same, scared of losing his limb. No documents were available of this earlier evaluation. 


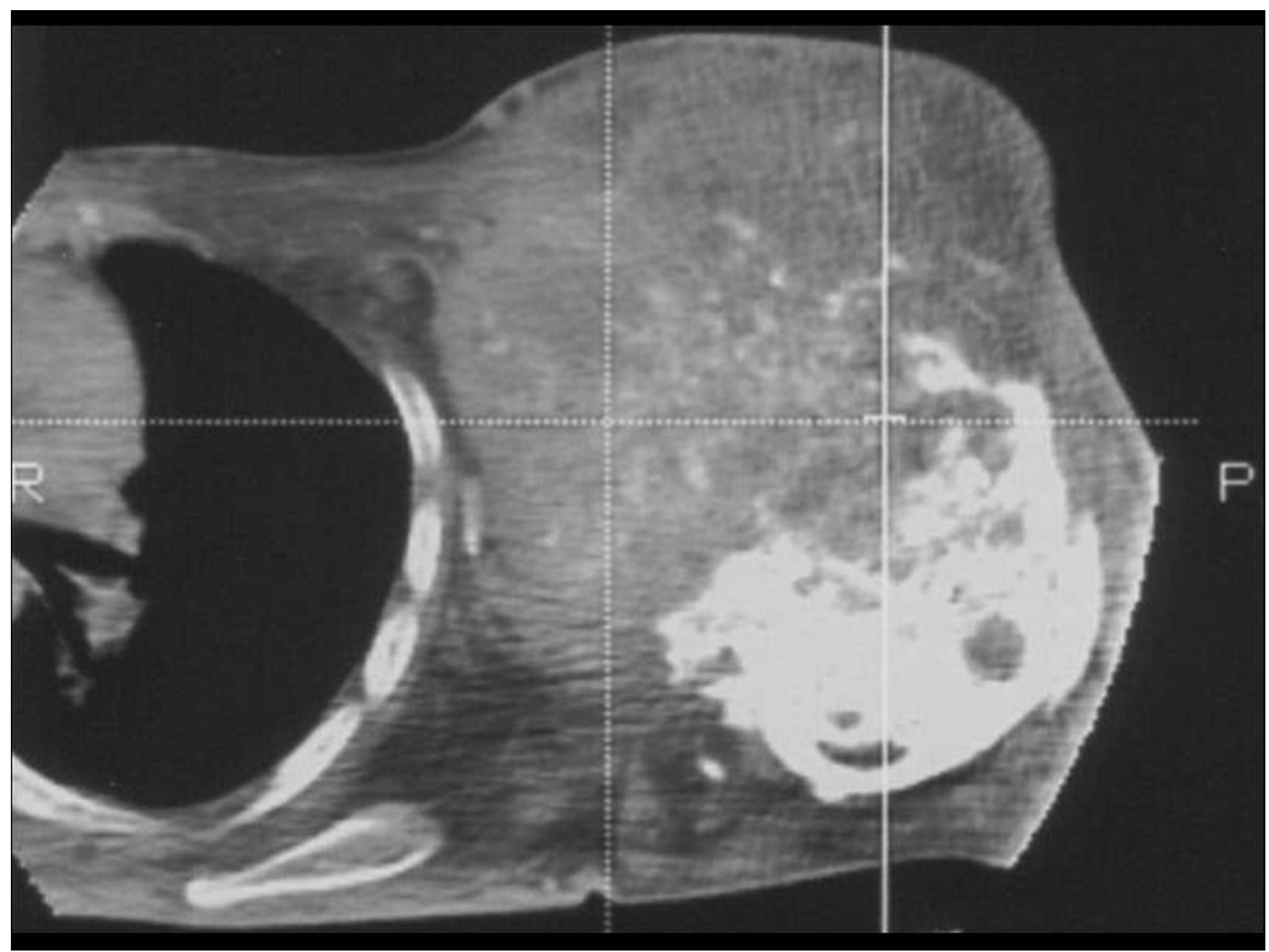

\section{Figure I}

CT scan showing a moderately enhancing tumor destroying the humeral head with a large extra-osseous component extending and infiltrating the surrounding muscles and soft tissues up to skin. Spotty calcification is evident

At presentation, the patient had restricted shoulder joint movement on the left side, nagging pain and excessive sweating in the skin over the swelling. On examination, there was an anteriorly placed large non tender swelling over the left shoulder arising from the humerus and involving the soft tissues with firm and soft areas. There was excessive sweating in the skin overlying the tumor, left upper limb, left side of neck and some areas over left upper chest. The skin over axillary region of the swelling was thickened. In addition, there were dilated veins and cutaneous varicosities around the swelling. There was no edema or venous engorgements of the left upper limb and radial pulse was well felt. A clinical diagnosis of a recent sarcomatous change in a benign tumor was entertained.
Roentgenogram of the part showed an expansile bone lesion of the upper end of left humerus with areas of calcification. CT scan of the part showed a large tumor of the humeral head [Fig 1]. Fine needle aspiration cytology and core needle biopsy of the swelling suggested a diagnosis of chondroblastoma. However, owing to rarity of such a presentation, sarcoma was still considered a possibility. There were no metastases on evaluation.

The patient underwent fore-quarter amputation. Intra operatively, the tumor was in close proximity to the lateral chest wall but it was possible to obtain adequate margins of the vessels and nerves at the thoracic outlet. The tumor measured $21 \times 16 \times 10$ centimeters [Fig 2]. Post operative histopathology showed features of chondroblastoma with 


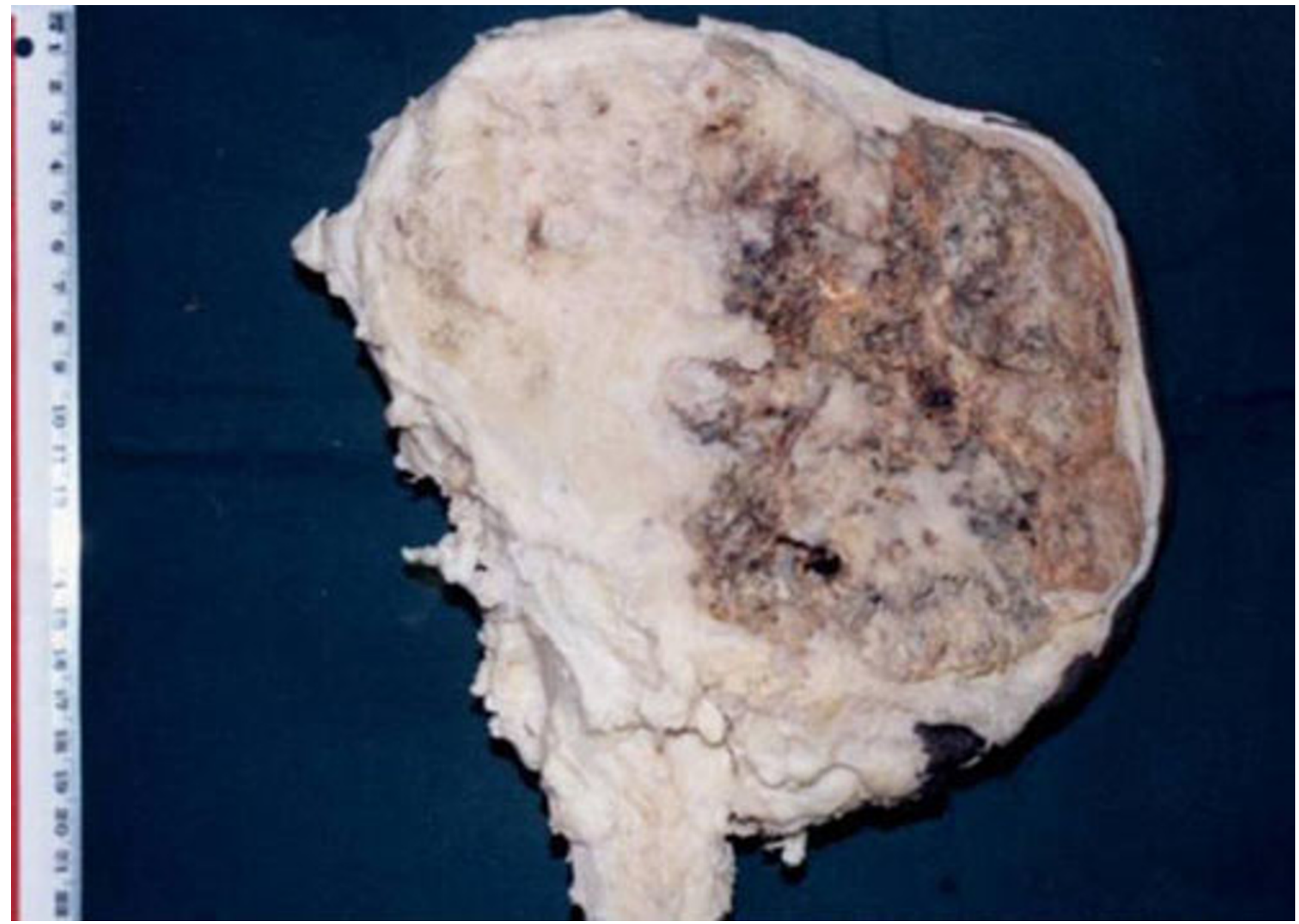

Figure 2

Saggital cut section of the resected specimen showing eccentric large tumor at upper end of humerus with margins closely abutting skin. Areas of chondroid and hemorrhage are seen. Focal calcification is evident.

extensive soft tissue involvement [Fig 3, 4]. The surgical margins were tumor free and there were no atypical features. The amputated stump was treated on a telecobalt unit to a dose of 50 Gray in 25 fractions over 5 weeks using tangential fields with a breast cone to spare the lungs. The patient is disease free and is on regular followup over the last five years.

\section{Discussion}

Most chondroblastomas are benign. Described variant behaviors include aggressiveness, metastasis, sarcomatous change and affliction of multiple bones [2-4]. Recurrences are more frequent and are generally in the range of $5 \%$ $10 \%$; most of the times they are due to inadequate primary surgery and are cured by further conservative surgical procedures [5]. Pathologically, an extensive extra cortical soft tissue involvement is termed aggressive.
'Atypical' indicates features of chondroblastoma with hemangiopericytoma like areas or presence of myxoid substance or spindle cells arranged in storiform pattern [6]. Unfortunately these 'atypical' features are not good predictors of future behavior of the disease. In a clinical setting, 'aggressive' has been used to denote a locally large or a recurrent lesion [7]. Most of the reported aggressive chondroblastomas are recurrent and are aggressive on recurrence [7-14]. In these cases, though there could be inherent 'tumor aggressiveness', significant iatrogenic factors contributing to the aggressiveness include breaching of cortex and accidental spillage at the time of curettage resulting in implantation of tumor tissue in soft tissues $[2,9,14]$. Hence, recurrence increases the chance of a chondroblastoma becoming 'aggressive'. Considering these factors, it is significant that only two of the earlier reported cases are non-recurrent and would qualify as a 


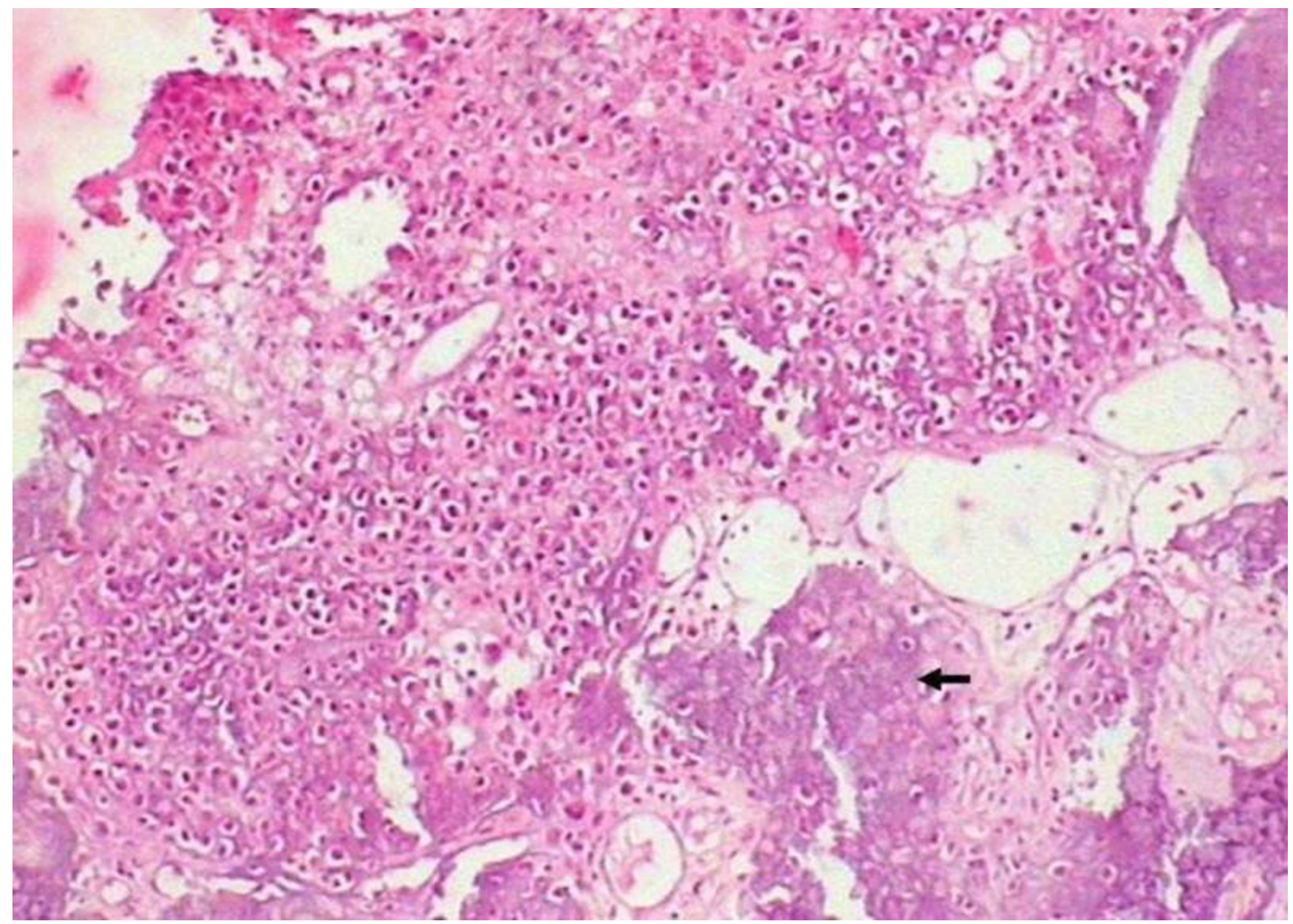

Figure 3

Photomicrograph of histopathology sections showing tumor cells with tumor cells in chondroid background with chicken wire calcification (indicated by arrow) $(\times 100)$

'primary' aggressive chondroblastoma [5,15]. Two other cases which were claimed as aggressive chondroblastomas were later diagnosed as chondrosarcomas by subsequent reviewers $[16,17]$. The present case would qualify as the third case of primary aggressive chondroblastoma on clinical and pathologic criteria. There were no pathological atypical features. The aggressive and metastatic behaviors of 'benign' chondroblastomas have been thoroughly studied in two extensive reviews $[1,2]$. In most of the metastatic chondroblastomas the behavior of the primary tumor has been 'aggressive' with rare exceptions; on the contrary, not all aggressive local lesions metastasize. This patient did not develop any local recurrence in the 5 year follow up. In addition, he did not develop metastasis in the 12 year period he harbored the disease or during follow-up.
There were neither signs of neurological involvement of the left upper limb nor were there any signs of venous flow impediment. The tumor was large, with extensive involvement of humerus, surrounding muscles and soft tissues up to skin. In addition there was encasement of axillary vessels and branches of brachial plexus. In view of these, a limb conservation procedure was not considered feasible and a fore-quarter amputation was performed.

Excessive perspiration could be due to an autonomic stimulation as the axillary vessels and brachial plexus were encased by the tumor. The excessive perspiration has been ascribed in another case where there was unilateral hyperhidrosis to pre-ganglionic autonomic stimulation [18]. Hyperhidrosis over the neck and upper chest subsided post surgically prior to institution of radiation. 


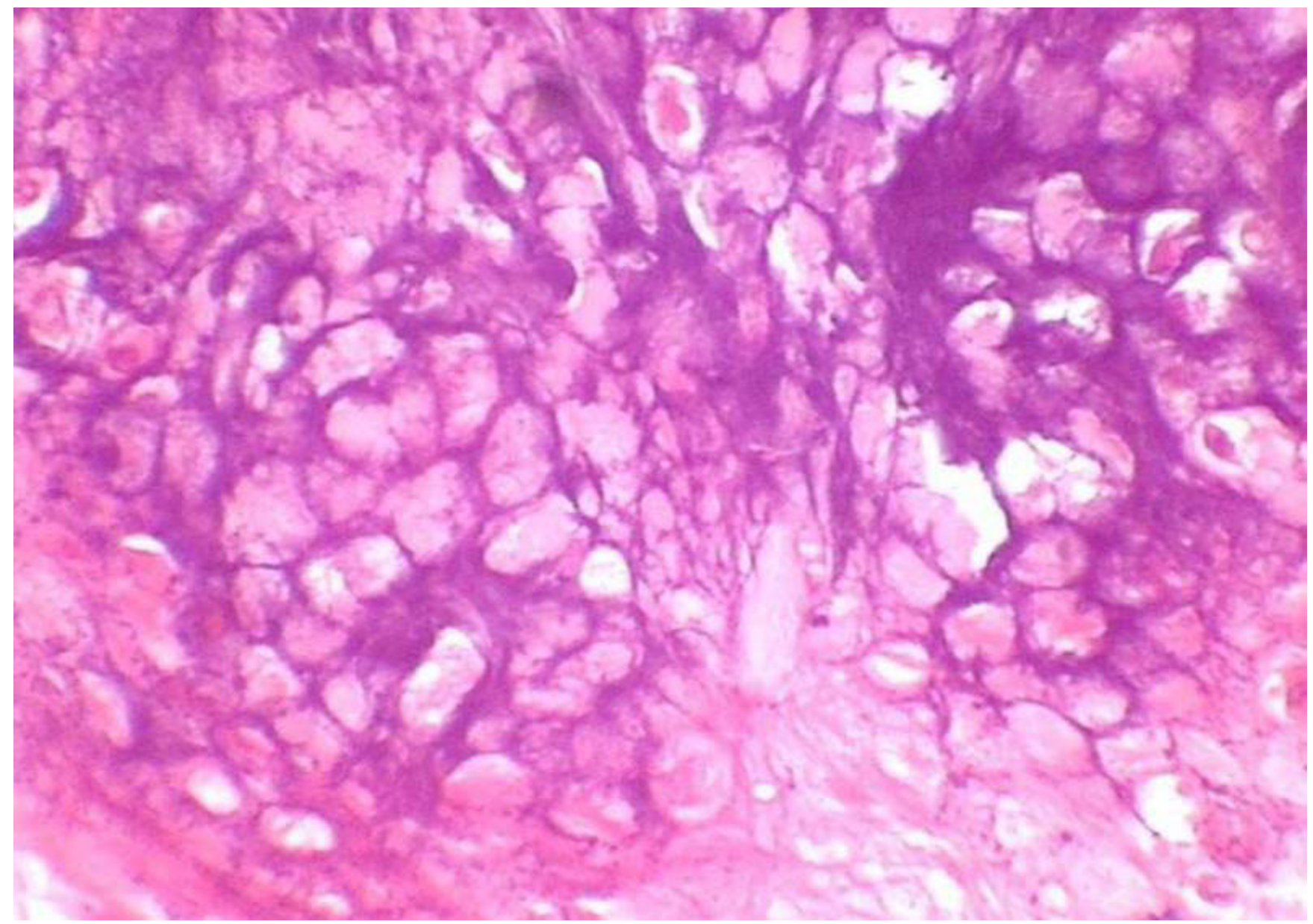

Figure 4

Photomicrograph of histopathology sections showing chicken wire or lace like calcification under magnification $(\times 400)$

On histopathological examination, all the features necessary to diagnose a chondroblastoma with certainty were present. The microscopic features included the chondroblast, osteoclast like giant cells, mitotic rate of less than 4 per high power field, islands of primitive chondroid and chicken wire calcification. There were no atypical features. Since aggressive chondroblastomas are rare, and some tumors reported as chondroblastomas were later diagnosed as chondrosarcomas, the microscopic picture was reviewed by two other pathologists independently.

The neurovascular bundle and the surgical margins were tumor free. However, in view of the large tumor size and close proximity to the chest wall, administering adjuvant radiation was deliberated upon. An additional factor considered was that it would be very difficult to treat a recurrence if one were to occur. Though post-irradiation sarcomas have been documented in chondroblastoma, they have occurred when the bone harboring the tumor has been directly irradiated [1]. In this patient, the risk of post radiation sarcoma would be very much akin to the chest wall radiation following mastectomy as the radiation administered was targeted to the amputated stump including the skin and soft tissues [19]. Having considered these factors, the possible benefits of radiotherapy outweighed the risks and patient received adjuvant irradiation.

This patient was harboring an untreated chondroblastoma for 12 years and the disease was allowed to exhibit its natural history. The inordinate delay in treatment cost him his limb. The unanswered question is whether all untreated chondroblastomas behave in this manner. Recent chromosomal studies suggest that there appears to be a preferential involvement of chromosomes 5 and 8 in chondroblastomas and that $8 \mathrm{q} 21$ abnormalities may pre- 
dict aggressive behavior [20]. Since only some of the aggressive chondroblastomas metastasize, it is possible that additional genetic changes determine the metastatic event.

\section{Conclusions}

Chondroblastomas are benign lesions but can be locally aggressive and rarely even metastatic disease has been documented. We report a third case of non-recurrent primary aggressive chondroblastoma. To our knowledge this is the largest aggressive chondroblastoma to be reported. This patient had to undergo a mutilating fore-quarter amputation due to inordinate delay in presentation. Early diagnosis and appropriate therapy can prevent recurrences and mutilating surgeries.

\section{Authors' contributions}

KH was the principal clinician who planned the evaluation and procedure, in addition to conceptualizing and drafting the article.

MGJ planned and administered radiation

NKA was the pathologist.

All authors read and approved the final manuscript.

\section{Acknowledgements}

Dr. Rekha V Kumar, Associate Professor of Pathology at the Kidwai Memorial Institute of Oncology (A Regional Cancer Center), Bangalore, INDIA was the reference pathologist. We wish to thank her for helping us with the pathologic study of the tumor. She confirmed the diagnosis independently.

Written consent was obtained from the patient for publication of study.

\section{References}

I. Mirra JM, Gold RH, Marcove RC: Bone Tumors: Diagnosis and Treatment JB Lippincott Company; 1980.

2. Kyriakos M, Land VJ, Penning HL, Parker SG: Metastatic chondroblastoma. Report of a fatal case with a review of the literature on atypical, aggressive, and malignant chondroblastoma. Cancer 1985, 55:1770-89.

3. Sirsat MV, Doctor VM: Benign chondroblastoma of bone. Report of a case of malignant transformation. J Bone Joint Surg $\mathrm{Br}$ 1970, 52:741-745.

4. Roberts PF, Taylor JG: Multifocal benign chondroblastomas: Report of a case. Hum Pathol 1980, I I:296-8.

5. Dahlin DC, Ivins JC: Benign chondroblastoma. A study of $\mathbf{2 5}$ cases. Cancer 1972, 30:40I-I3.

6. Kurt AM, Unni KK, Sim FH, McLeod RA: Chondroblastoma of bone. Hum Pathol 1989, 20:965-76.

7. Mirra JM, Ulich TR, Eckardt JJ, Bhuta S: "Aggressive" chondroblastoma. Light and ultramicroscopic findings after en bloc resection. Clin Orthop 1983, I 78:276-84.

8. Accadbled F, Brouchet A, Salmeron F, Darodes P, Cahuzac JP, Sales De Gauzy ]: [Recurrent aggressive chondroblastoma: two cases and a review of the literature]. Rev Chir Orthop Reparatrice Appar Mot 200I, 87:718-23.

9. Coleman SS: Benign Chondroblastoma with recurrent soft-tissue and intra-articular lesions. Report of a case. J Bone Joint Surg Am 1966, 48: 1554-60.
10. Hull MT, Gonzalez-Crussi F, DeRosa GP, Graul RS: Aggressive chondroblastoma. Report of a case with multiple bone and soft tissue involvement. Clin Orthop 1977, I 26:26I-5.

II. Khan LB, Wood FM, Ackerman LV: Malignant chondroblastoma. Report of two cases and review of literature. Arch Pathol 1969, 88:37I-6.

12. Posl M, Amling M, Ritzel H, Werner M, Stenzel I, Delling G: [Morphologic characteristics of chondroblastoma. A retrospective study of $\mathbf{5 6}$ cases of the Hamburg bone tumor register]. Pathologe 1996, 17:26-34.

13. Povysil C, Matejovsky Z, Zidkova H, Trnka V: [Aggressive chondroblastoma]. Acta Chir Orthop Traumatol Cech 1993, 60:232-6.

14. Shoji H, Miller TR: Benign chondroblastoma with soft-tissue recurrence. N Y State J Med I97I, 7 I:2786-9.

15. Wright JL, Sherman MS: An unusual chondroblastoma. J Bone Joint Surg Am 1964, 46:567-600.

16. McLaughlin RE, Sweet DE, Webster T, Merritt WM: Chondroblastoma of the pelvis suggestive of malignancy. Report of an unusual case treated by wide pelvic excision. J Bone Joint Surg Am 1975, 57:549-5I.

17. Varma BP, Gupta IM: Atypical chondroblastoma of tibia. Report of a recurrent lesion. Clin Orthop 1972, 89:24I-5.

18. Seline PC, Jaskierny DJ: Cutaneous metastases from a chondroblastoma initially presenting as unilateral palmar hyperhidrosis. J Am Acad Dermatol 1999, 40:325-7.

19. Weatherby RP, Dahlin DC, Ivins JC: Postradiation sarcoma of bone. Mayo Clin Proc 1981, 56:294-306.

20. Swarts SJ, Neff JR, Johansson SL, Nelson M, Bridge JA: Significance of abnormalities of chromosomes 5 and 8 in chondroblastoma. Clin Orthop 1998, 349:189-93.

\section{Pre-publication history}

The pre-publication history for this paper can be accessed here:

http://www.biomedcentral.com/1471-2474/5/9/prepub
Publish with Biomed Central and every scientist can read your work free of charge

"BioMed Central will be the most significant development for disseminating the results of biomedical research in our lifetime. "

Sir Paul Nurse, Cancer Research UK

Your research papers will be:

- available free of charge to the entire biomedical community

- peer reviewed and published immediately upon acceptance

- cited in PubMed and archived on PubMed Central

- yours - you keep the copyright

Submit your manuscript here:

http://www.biomedcentral.com/info/publishing_adv.asp
BioMedcentral 